\title{
PENGARUH MODEL PEMBELAJARAN KOOPERATIF TIPE NUMBERED HEAD TOGETHER TERHADAP HASIL BELAJAR CHEST PASS BOLA BASKET
}

\author{
Andika Yudha Putra Santoso ${ }^{1}$, I. K. Budaya Astra ${ }^{2}$, I. G. Suwiwa ${ }^{3}$ \\ ${ }^{1,2,3}$ Program Studi Pendidikan Jasmani Kesehatan dan Rekreasi \\ Universitas Pendidikan Ganesha \\ Singaraja, Indonesia \\ Email : santosoyudha4@gmail.com ${ }^{1}$, astra budaya@yahoo.com², \\ suwiwagede@gmail.com ${ }^{3}$
}

\begin{abstract}
ABSTRAK
Penelitian ini bertujuan untuk mengetahui pengaruh model pembelajaran kooperatif tipe numbered head together terhadap hasil belajar chest pass bola basket pada siswa kelas XI SMA Negeri 2 Singaraja. Jenis penelitian adalah eksperimen sungguhan (true experimental) dengan menggunakan desain penelitian the randomized pretest-posttest control group the same subject design. Pengambilan sampel menggunakan teknik random sampling. Kelas yang menjadi sampel penelitian adalah kelas XI-MIPA 2 sebagai kelompok control dan XI-MIPA 4 sebagai kelompok eksperimen. Pengumpulan data hasil belajar diperoleh melalui tes objektif, observasi dan unjuk kerja. Analisis data yang digunakan adalah uji-t dengan bantuan SPSS 16.0 for Windows. Analisis data menunjukkan bahwa dari hasil rata-rata gain score pada kelas kelompok eksperimen adalah 6,8824 , lebih tinggi dari kelas kelompok control yaitu 4,2941. Hasil uji-t menunjukkan nilai sig pada kolom sig (2-tailed) dan baris equal variances assumed sebesar 0.000. Nilai sig ini lebih kecil dari pada 0,05 sehingga sehingga $\mathrm{H}_{0}$ ditolak dan $\mathrm{H}_{a}$ diterima. Dengan demikian, penerapan model pembelajaran kooperatiftipe NHT berpengaruh signifikan terhadap peningkatan hasil belajar chest pass bola basket. Disarankan kepada guru PJOK agar menerapkan model pembelajaran kooperatif tipe $\mathrm{NHT}$ dalam proses pembelajaran materi chest pass bola basket karena terbukti berpengaruh terhadap peningkatan hasil belajar siswa.
\end{abstract}

Kata Kunci: NHT, Hasil Belajar, Bola Basket

\section{ABSTRACT}

This study aims to determine the effect of the numbered head together type of cooperative learning model on basketball chest pass learning outcomes in class XI students of SMA Negeri 2 Singaraja. This type of research is a true experimental (true experimental) using the randomized pretest-posttest control group research design the same subject design. Sampling using a random sampling technique. Classes that became the study sample were class XI-MIPA 2 as a control group and XI-MIPA 4 as an experimental group. Data collection of learning outcomes is obtained through objective tests, observations and performance. Analysis of the data used is the t-test with the help of SPSS 16.0 for Windows. Data analysis showed that the average gain score in the experimental group class was 6.8824 , higher than the control 
group class at 4.2941. T-test results show the sig value in the sig (2-tailed) column and the equal variances assumed row of 0,000 . This sig value is smaller than 0.05 so that $\mathrm{H}_{\circ}$ is rejected and $\mathrm{H}_{a}$ is accepted. Thus, the application of the NHT type cooperative learning model has a significant effect on improving basketball chest pass learning outcomes. It is recommended to PJOK teachers to apply NHT type cooperative learning models in the learning process of basketball chest pass material because it is proven to have an effect on improving student learning outcomes.

Keywords: NHT, Learning Outcomes, Basketball

\section{PENDAHULUAN}

Pendidikan merupakan usaha sadar dan terencana untuk menyiapkan dan mengembangkan potensi peserta didik melalui kegiatan bimbingan, pengajaran dan latihan agar peserta didik di masa yang akan dating dapat berguna bagi dirinya, masyarakat, bangsa, dan Negara. Peranan PJOK sangatlah penting untuk tumbuh kembang fisik, mental, dan juga pengetahuannya. Maka dari itu, pendidikan jasmani tidak akan pernah lepas dari proses pembelajaran di sekolah. Peranan guru (dalam Slameto, 2003:97), memiliki tugas dalam memberikan dorongan, bimbingan, serta memfasilitasi belajar bagi siswa untuk mencapai tujuan. Pada PJOK di sekolah, apabila guru ingin mendapakan respon/hasil yang baik dari proses pembelajaran yang telah dilaksanakan, maka siswa harus diberikan stimulus yang baik pula. Oleh karena itu, walaupun siswa adalah penentu terjadinya atau tidak terjadinya proses belajar, namun pengelolaan dari guru PJOK tersebut juga sangat berpengaruh terhadap proses yang sedang/akan djalankan beserta hasilnya.

Materi bola basket merupakan salah satu materi yang diajarkan kepada kelas XI SMA Negeri 2 Singaraja. Berdasarkan hasil observasi yang dilakukan oleh peneliti, hasil belajar siswa kelas XI SMA Negeri 2 Singaraja khususnya pada pembelajaran teknik chest pass masih belum memenuhi
Kriteria Ketuntasan Minimal (KKM).

Dari total 310 siswa kelas XI dengan rincian nilai dari 10 kelas, didapat yang belum mencapai KKM dengan nilai 75 sebagai berikut: kelas IPA 1 tidak tuntas 12 orang dari 32 siswa, IPA 2 tidak tuntas 17 orang dari 34 siswa, IPA 3 tidak tuntas 16 orang dari 33 siswa, IPA 4 tidak tuntas 18 orang dari 34 siswa, IPA 5 tidak tuntas 15 dari 32 siswa, IBB 1 tidak tuntas 11 dari 26 siswa, IBB 2 tidak tuntas 10 dari 29 siswa, IPS 1 tidak tuntas 9 dari 29 siswa, IPS 2 tidak tuntas 13 orang dari 30 siswa, dan IPS 3 tidak tuntas 14 dari 31 siswa.

Kualitas proses pembelajaran menentukan hasil belajar, oleh karena itu proses pembelajaran harus dirancang untuk mampu mengembangkan hasil belajar yang diperlukan siswa. Hasil belajar yang demikian adalah hasil belajar yang memiliki dimensi jangka panjang yang dapat membekali siswa dalam kehidupan dan belajar sepanjang hayat, yaitu kemampuan berpikir, kecakapan hidup, psikomotor, dan sudah barang tentu hasil belajar. Pembelajaran yang efesien sangat diperlukan agar hasil belajar peserta didik mencapai ketuntasan yang diharapkan. Pembelajaran PJOK akan sangat bermakna apabila guru dan murid saling terlibat akif dalam proses tersebut. Melalui keterampilan dan keahlian yang dimiliki oleh seorang guru, maka diharapkan guru mampu dan terampil memilih model pembelajaran yang tepat sesuai dengan karakteristik peserta didik, 
sehingga diperoleh hasil belajar yang sesuai dengan target yang akan dicapai dalam kurikulum.

Berdasarkan hasil pengamatan dan observasi di SMA Negeri 2 Singaraja, diperoleh beberapa faktor, di antaranya: kurangnya kerjasama dalam berinteraksi antara guru dengan siswa dan antara siswa dengan siswa lainnya, yang menyebabkan siswa tidak memiliki kesempatan untuk mengemukakan pendapat- pendapat mereka dalam pembelajaran, kurangnya keantusiasan siswa dalam mengikuti proses pembelajaran PJOK, model pembelajaran masih menggunakan model konvensional dengan metode ceramah yang cenderung monoton sehingga membuat siswa merasa bosan, serta kurangnya diskusi antara siswa dengan guru terkait materi PJOK yang telah disampaikan.

Model pembelajaran kooperatif tipe NHT yang dipelopori oleh Spencer Kagen pada tahun 1993 ini dipilih, karena model pembelajaran ini mengutamakan aktivitas peserta didik dalam mencari, mengolah, dan melaporkan informasi dari berbagai sumber yang akhirnya dipresentasikan di depan kelas.

Model pembelajaran kooperatif tipe NHT adalah suatu pendekatan untuk melibatkan lebih banyak siswa dalam menelaah materi yang tercakup dalam suatu pelajaran dan mengecek pemahaman mereka terhadap isi pelajaran tersebut (Trianto, 2007:62). Melalui model pembelajaran kooperatif tipe NHT, diharapkan dapat membantu mengatasi kesulitan peserta didik.

Adapun kelebihan dari model pembelajaran kooperatif tipe NHT adalah: (1) setiap siswa menjadi siap semua dalam pembelajaran, (2) adanya interaksi antar siswa melalui diskusi kelompok dalam menyelesaikan masalah, (3) siswa yang pandai dapat mengajari siswa yang kurang pandai, dan (3) tidak ada dominasi dalam kelompok, karena setiap siswa mendapat kesempatan mengembangkan kemampuannya baik dalam berdiskusi, dan bertanya.

Dalam hal ini guru berperan sebagai fasilitator dalam membimbing siswa , sehingga siswa mampu menemukan mampu menemukan dan memecahkan masalah.

Penelitian ini juga dikuatkan oleh hasil penelitian-penelitian sebelumnya, diantaranya 1) Suarjuliasa (2017) menemukan, bahwa dengan penerapan model pembelajaran kooperatif tipe numbered head together (NHT) berpengaruh terhadap hasil belajar teknik dasar pasing kontrol sepak bola pada siswa kelas VII 10 di SMP Negeri 2 Singaraja. Di mana hasil uji-t adalah $p=$ 0,000 , yang berarti berpengaruh secara signifikan. Hasil pengujian hipotesis menggunakan uji-t menunjukkan, bahwa kelompok eksperimen diperoleh dengan nilai rata-rata 0.67 , sedangkan pada kelompok kontrol diproleh nilai rata-rata 0.34. 2) Dewi (2017) menemukan, bahwa dengan model pembelajaran kooperatif tipe numbered head together (NHT) berpengaruh terhadap hasil belajar teknik dasar passing bola basket. Kelompok eksperimen memperoleh nilai rata-rata 0.581, sedangkan kelompok kontrol memperoleh nilai rata-rata 0.396. Angka signifikan yang diperoleh melalui uji t (ttest) adalah $0.000(\mathrm{p}<0,05)$. 3) Fajrin, dkk (2014) menyimpulkan, bahwa pembelajaran dengan menggunakan model kooperatif tipe Numbered Head Together (NHT) memberikan pengaruh yang signifikan terhadap hasil belajar dribbling sepakbola yaitu sebesar 23,53 \%. 4) Fariz (2017) menyimpulkan, bahwa bahwa ada pengaruh penggunaan pembelajaran tipe Numbered Head Together terhadap hasil belajar siswa kelas V SD Negeri 6 Metro Utara Tahun Ajaran 2016/2017.. Hal ini ditunjukkan dengan nilai rata-rata hasil belajar siswa yang mengikuti pembelajaran IPS menggunakan pembelajaran tipe Numbered Head Together pada kelas eksperimen (VA) yaitu 85,0 lebih tinggi dari nilai rata-rata hasil belajar siswa yang 
mengikuti pembelajaran konvensional pada kelas kontrol (VB) yang hanya mendapat nilai 68,7.

Berdasarkan uraian di atas, maka peneliti mengadakan penelitian dengan judul Pengaruh Model Pembelajaran Kooperatif Tipe Numbered Head Together (NHT) terhadap Hasil Belajar Chest Pass Bola Basket Pada Siswa Kelas XI SMA Negeri 2 Singaraja Tahun Ajaran 2018/2019.

Adapun manfaat menggunakan model pembelajaran NHT bagi guru yaitu dapat meningkatkan wawasan dan keterampilan guru penjasorkes dalam menerapkan model pembelajaran kooperatif tipe Numbered Head Together (NHT) pada cheast pass basket. Sedangkan manfaatnya bagi sokolah yaitu, dapat membantu sekolah dalam meningkatkan pemberdayaan kecakapan hidup para siswanya sehingga diharapkan lebih dapat bersaing dalam kompetensi antar sekolah baik untuk terjun ke masyarakat maupun untuk kepentingan melanjutkan study ke jenjang yang lebih tinggi. Manfaat bagi peneliti yaitu memberikan pengalaman bagi peneliti dalam menghadapi situasi dan kondisi dalam proses pembelajaran dan menambah wawasan bagi peneliti mengenai model pembelajaran kooperatif dalam pembelajaran PJOK.

\section{METODE PENELITIAN}

Jenis penelitian ini $\begin{array}{r}\text { adalah } \\ \text { (true }\end{array}$
eksperimen
experimental), yaitu adanya kelompok
control dan sampel yang dipilih secara
random (Sugiono, 2012:12). Eksperimen
sesungguhnya ini digunakan dalam
penelitian ini karena untuk menyelidiki
adanya hubungan sebab akibat antara
satu atau lebih kelompok eksperimen dan
membandingkan hasilnya dengan satu
atau lebih kelompok control yang tidak
dikenai perlakuan (Kanca, 2010:86).

Desain penelitian yang digunakan dalam penelitian ini adalah the randomized pretest-posttest control group the same subject design.

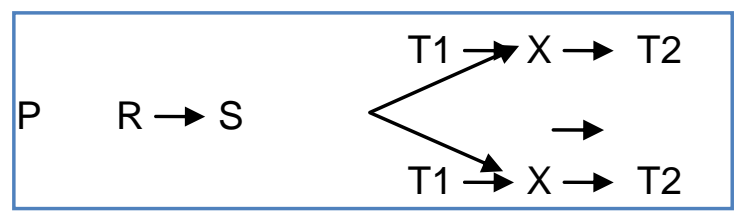

Gambar 1. Rancangan Penelitian Penelitian

(Sumber: Kanca, 2010: 87)

Subjek dalam penelitian ini adalah siswa kelas XI SMA Negeri 2 Singaraja tahun ajaran 2018/2019 berjumlah 310 siswa yang terbagi menjadi 10 kelas. Dalam pengambilan sampel dari populasi, peneliti menggunakan cara probabilitas sampling (random sampling), yang di dalamnya mengarah pada simple random sampling.

Peneliti menggunakan teknik tersebut dikarenakan populasi yang ditentukan ialah homogen (kelas XI saja). Kemudian diambil 2 (dua) kelas sebagai sampel dengan diundi. Terpilih kelas XIMIPA 2 sebagai kelompok kontrol dan kelas XI-MIPA 4 sebagai kelompok perlakuan. Perlakuan diberikan sebanyak 3 kali pada kelas eksperimen oleh peneliti dan 3 kali pada kelas kontrol oleh guru penjasorkes yang mengajar secara bersamaan.

Teknik pengumpulan data pada penelitian ini menggunakan hasil belajar pretest-posttest, observasi , dan unjuk kerja. Sedangkan Analisis data pada penelitian ini menggunakan program SPSS 16.0 for windows. Hasil dari nilai pretest dan posttest akan dianalisis menggunakan analisis statistik parametrik yaitu uji-t. Sebelum melakukan analisis menggunakan uji-t, terlebih dahulu melakukan uji prasyarat analisis yaitu uji normalitas data dan uji homogenitas varians. Nilai pretest tersebut dapat juga dilakukan normalisasi dengan nilai postest. Nilai tersebut dinormalisasikan 
dengan menggunakan gain skor ternormalisasi (Normalizzed Gain Score), di mana gain skor dilaksanakan sebelum uji prasyarat analisis dan uji-t.

\section{HASIL DAN PEMBAHASAN}

Penelitian ini dilaksanakan sebanyak tiga kali pertemuan dimulai pada tanggal 1 Oktober 2018 sampai dengan 14 Nopember 2018. Pertemuan pertama memberikan tes awal (pretest) dan perlakuan I, pertemuan ke dua

Tabel 1. Hasil Uji Normalitas Gain Score memberikan perlakuan II dan pertemuan ke tiga memberikan perlakuan III dan tes akhir (posttest).

Sebelum dilakukan uji hipotesis, terlebih dahulu dilakukan uji normalitas sebaran data dan uji homogenitas varians, sebagai pengujian prasyarat terhadap sebaran data. Uji normalitas data menggunakan teknik statistik Kalmogorov-Smirnov dan Shapiro-Wilk. Hasil uji normalitas Gain Score ditampilkan pada Tabel 1 berikut.

\begin{tabular}{llcccccc}
\hline \multirow{2}{*}{ Kelas } & \multicolumn{3}{c}{ Kolmogorov-Smirnov } & \multicolumn{3}{c}{ Shapiro-Wilk } \\
\cline { 3 - 8 } & & Statistic & df & Sig. & Statistic & df & Sig. \\
\hline \multirow{2}{*}{ Gain score } & Kontrol & 0,137 & 34 & 0,110 & 0,943 & 34 & 0,077 \\
& Eksperimen & 0,096 & 34 & 0,200 & 0,940 & 34 & 0,061 \\
\hline
\end{tabular}

Berdasarkan Tabel di atas, diperoleh harga sig dari kelas kontrol dan kelas eksperimen untuk analisis Kolmogorov-Smirnov masing-masing 0,110 dan 0,200 . Nilai sig dari kedua kelas ini lebih besar dari 0,05. Dengan demikian data gain score dari kedua kelas berdistribusi normal.

Uji homogenitas data dilakukan dengan menggunakan teknik statistik Levene's Test.Hasil Uji Homogenitas Varians diperoleh pada Tabel 2 berikut.

Tabel 2. Hasil Uji Homogenitas Varians

\begin{tabular}{cccc}
\hline $\mathbf{F}$ & df1 & df2 & Sig. \\
\hline 3,327 & 1 & 66 & 0,073 \\
\hline
\end{tabular}

Berdasarkan hasil analisis pada Tabel Levene's Test of Equality of error Variances diperoleh $\mathrm{F}=3,327$, df $1=1$, df2 $=66$, dan sig atau $\mathrm{p}$-value $=0,073>$ 0,05 . Dengan demikian hasil data gain score dari kelompok kontrol dan kelompok eksperimen homogen.

Selanjutnya dilakukan uji hipotesis menggunakan uji-t dengan SPSS 16.0 for Windows pada Tabel 3 berikut. 
Tabel 3. Hasil Uji Independent Sample t Test

\begin{tabular}{|c|c|c|c|c|c|c|c|c|c|c|}
\hline & & \multirow[t]{2}{*}{$\mathbf{F}$} & \multirow[t]{2}{*}{ Sig. } & \multirow[t]{2}{*}{$\mathbf{t}$} & \multirow[t]{2}{*}{ df } & \multirow{2}{*}{$\begin{array}{l}\text { Sig. } \\
(2- \\
\text { tailed } \\
\text { ) }\end{array}$} & \multirow[t]{2}{*}{$\begin{array}{c}\text { Mean } \\
\text { Differenc } \\
e\end{array}$} & \multirow{2}{*}{$\begin{array}{l}\text { Std. } \\
\text { Error } \\
\text { Differe } \\
\text { nce }\end{array}$} & \multicolumn{2}{|c|}{$\begin{array}{c}\text { 95\% Confidence } \\
\text { Interval of the } \\
\text { Difference }\end{array}$} \\
\hline & & & & & & & & & Lower & Upper \\
\hline \multirow[b]{2}{*}{$\begin{array}{c}\text { Gain_Sc } \\
\text { ore }\end{array}$} & $\begin{array}{c}\text { Equal } \\
\text { variances } \\
\text { assumed }\end{array}$ & $\begin{array}{c}3,3 \\
27\end{array}$ & $\begin{array}{c}0,07 \\
3\end{array}$ & $\begin{array}{c}- \\
4,178\end{array}$ & 66 & 0,000 & $-2,58824$ & $\begin{array}{c}0,6194 \\
9\end{array}$ & $-3,82509$ & $-1,35138$ \\
\hline & $\begin{array}{c}\text { Equal } \\
\text { variances } \\
\text { not } \\
\text { assumed }\end{array}$ & & & $\begin{array}{c}- \\
4,178\end{array}$ & 61,209 & 0,000 & $-2,58824$ & $\begin{array}{c}0,6194 \\
9\end{array}$ & $-3,82690$ & $-1,34957$ \\
\hline
\end{tabular}

Berdasarkan Tabel di atas, nilai sig pada kolom sig (2-tailed) dan baris equal variances assumed sebesar 0.000 . Nilai sig ini lebih kecil dari pada 0,05, sehingga $\mathrm{H}_{0}$ ditolak dan $\mathrm{H}_{1}$ diterima. Hasil ini menunjukkan adanya perbedaan hasil belajar antara siswa yang pembelajarannnya menggunakan model pembelajaran kooperatif tipe NHT dengan siswa yang pembelajarannya menggunakan model pembelajaran konvensional..

Rerata hasil analisis game score hasil belajar siswa baik pretest maupun posttest dari kedua kelas ditampilkan pada Tabel 4 berikut.

Tabel 4. Hasil Rekapitulasi Gain Score Hasil Belajar Siswa

\begin{tabular}{lccccc}
\hline \multicolumn{1}{c}{ Kelas } & Mean & N & $\begin{array}{c}\text { Std. } \\
\text { Deviation }\end{array}$ & Minimum & Maximum \\
\hline Kontrol & 4,2941 & 34 & 2,16 & 1,00 & 8,00 \\
Eksperimen & 6,8824 & 34 & 2,88 & 2,00 & 11,00 \\
\hline
\end{tabular}

Berdasarkan Tabel di atas, diketahui bahwa nilai mean dari gain score kelas eksperimen lebih besar dibandingkan nilai mean gain score kelas kontrol. Nilai standar deviasi dari gain score kelas eksperimen dan kelas kontrol masing-masing adalah 2,88 dan 2,16. Hal ini menunjukkan sebaran data pada kelas eksperimen lebih bervariasi dibandingkan sebaran data pada kelas kontrol.

Hasil diskriptif di atas diperlihatkan dengan histogram data Gain Score kelompok Kontrol dan histogram Gain Score kelompok eksperimen, disertai kurva normal untuk kelas kontrol dan kelas eksperimen.

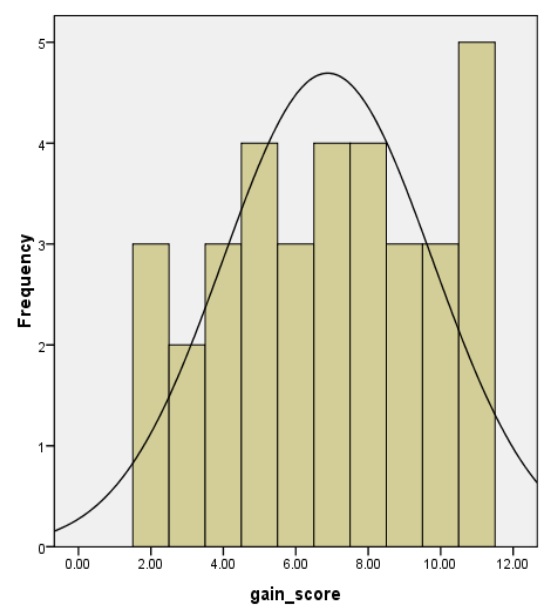

Gambar 2. Histogram Data Gain Score Kelompok Eksperimen 


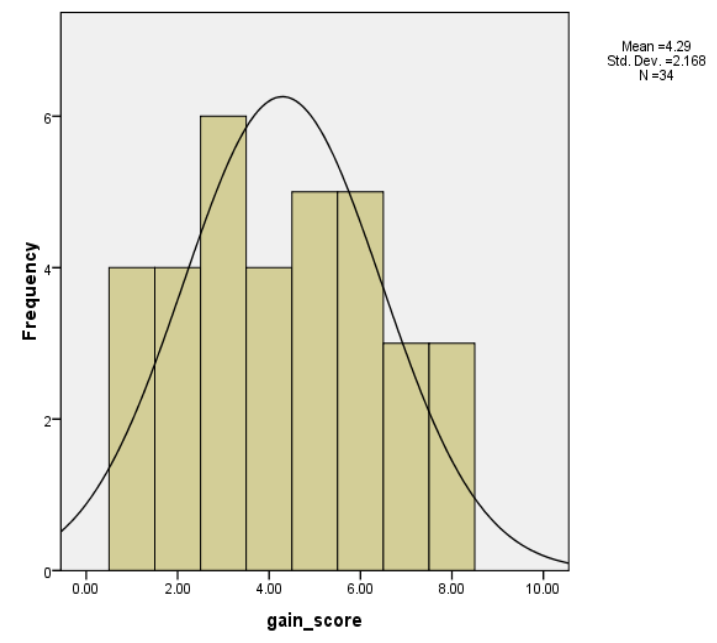

Gambar 3. Histogram Data Gain Score Kelompok Kontrol

Dalam penelitian ini masingmasing kelompok penelitian diberikan perlakuan yang berbeda, dimana kelompok eksperimen diberikan perlakuan berupa model pembelajaran kooperatif tipe NHT sedangkan pada kelompok kontrol diberikan perlakuan model pembelajaran konvensional. Pembelajaran koperatif tipe NHT menghendaki siswa bekerja saling membantu dalam kelompok kecil dan lebih dicirikan oleh penghargaan kooperatif daripada penghargaan individual. Pendekatan ini dirancang untuk mengembangkan indikator-indikator kunci pembelajaran kooperatif yang meliputi saling ketergantungan positif, tanggung jawab perseorangan, dan partisipasi yang merata. Dalam pendekatan struktural, tujuan kognitif yang hendak dicapai adalah berupa informasi akademik sederhana, sedangkan tujuan sosialnya adalah keterampilan kelompok dan keterampilan sosial. Struktual tim beranggotakan 3-5 orang tiap kelompok. Dalam pembelajaran kelompok control yang dibelajarkan menggunakan model pembelajaran konvensional menekankan pada guru sebagai pusat informasi dan siswa sebagai penerima informasi. Situasi kelas sebagian besar masih berfokus pada guru sebagai sumber utama pengetahuan, serta pengguanaan model ceramah sebagai pilihan utama strategi belajar mengajar.

Berdasarkan pengamatan peneliti pada saat pembelajaran berlangsung di kelompok eksperimen, pembelajaran diarahkan untuk memberikan perhatian terhadap pemahaman siswa tentang teknik dasar passing bounce pass di dalam mengikuti pelajaran. Aktivitas siswa yang lebih positif dalam menelaah materi suatu pelajaran pada kegiatan belajar menjadi salah satu faktor yang membuat rata-rata skor yang diperoleh siswa pada kelompok eksperimen lebih besar daripada rata-rata skor yang diperoleh siswa pada kelompok kontrol.

$\mathrm{Hal}$ ini sejalan dengan pernyataan Trianto (2007: 82) yang menyatakan NHT dirancang untuk melibatkan lebih banyak siswa dalam menelaah materi yang tercakup dalam suatu pelajaran dan mengecek pemahaman mereka terhadap isi pelajaran tersebut. Model pembelajaran kooperatif tipe NHT dirancang untuk mempengaruhi pola interaksi siswa dan alternative terhadap struktur kelas tradisional.

Pembelajaran di kelompok kontrol dilakukan dengan model ceramah oleh guru dalam penyampaian materi kemudian mendemonstrasikan materi pelajaran dan menugaskan siswa untuk mempraktikkan materi yang diajarkan. Melalui penugasan tersebut diharapkan siswa mampu memahami dan melakukan gerakan dengan benar.

Berdasarkan pengamatan peneliti pada saat pembelajaran berlangsung, model konvensional yang diterapkan di kelompok kontrol pada dasarnya menuntun siswa untuk dapat memahami dan mempraktikan gerakan dengan benar. Namun dengan penggunaan model ceramah proses penyampaian materi menyebabkan masih banyak siswa yang kurang aktif dalam proses pembelajaran yang mengakibatkan kurangya partisipasi siwa secara 
menyeluruh, sehingga pemahaman dan keterampilan siswa dalam melakukan teknik dasar passing bola basket menjadi terhambat dan kurang merata.

Hal ini berbeda dengan pembelajaran pada kelompok eksperimen yang menggunakan model pembelajaran kooperatif tipe NHT dimana siswa termotivasi mengikuti pelajaran karena model pembelajaran NHT membentuk kelompok-kelompok belajar dengan memberikan nomor kepada siswa dalam tiap-tiap kelompok dan memberikan penghargaan bagi siswa atau kelompok yang berprestasi.

Dengan demikian, siswa akan berlomba-lomba untuk menjadi yang terbaik dalam proses pembelajaran, sehingga rata-rata skor siswa di kelompok eksperimen lebih tinggi dari pada ratarata skor siswa pada kelompok kontrol.

Hasli penelitian yang relevan menggunakan model pembelajaran Numbered Head Together (NHT) ini juga dilakukan oleh peneliti sebelumnya, yaitu: (1) Yanuar (2014) menyimpulkan, bahwa pembelajaran dengan menggunakan model kooperatif tipe Numbered Head Together (NHT) memberikan pengaruh yang signifikan terhadap hasil belajar dribbling sepakbola yaitu sebesar 23,53 \%. (2) Fariz (2017) menyimpulkan, bahwa bahwa ada pengaruh penggunaan pembelajaran tipe Numbered Head Together terhadap hasil belajar siswa kelas V SD Negeri 6 Metro Utara Tahun Ajaran 2016/2017.. Hal ini ditunjukkan dengan nilai rata-rata hasil belajar siswa yang mengikuti pembelajaran IPS menggunakan pembelajaran tipe Numbered Head Together pada kelas eksperimen (VA) yaitu 85,0 lebih tinggi dari nilai rata-rata hasil belajar siswa yang mengikuti pembelajaran konvensional pada kelas kontrol (VB) yang hanya mendapat nilai 68,7. (3) Gede (2017) bahwa penerapan model pembelajaran kooperatif tipe NHT berpengaruh sangat signifikan terhadap peningkatan hasil belajar passing atas bola voli pada siswa kelas XII MIA SMA Negeri 2 Singaraja tahun pelajaran 2016/2017, dan 4) Dewi, dkk (2017) menemukan bahwa dengan model pembelajaran kooperatif tipe numbered head together (NHT) berpengaruh terhadap hasil belajar teknik dasar passing bola basket. Kelompok eksperimen memperoleh nilai rata-rata 0.581, sedangkan kelompok kontrol memperoleh nilai rata-rata 0.396. Angka signifikan yang diperoleh melalui uji t (ttest) adalah $0.000(p<0,05)$.

\section{PENUTUP}

Berdasarkan rumusan masalah, tujuan penelitian serta hasil penelitian, maka secara garis besar dapat diambil kesimpulan bahwa terdapat pengaruh yang signifikan model pembelajaran kooperatif Numbered Head Together (NHT)terhadap hasil belajar chest pass bola basket pada siswa kelas XI SMA Negeri 2 Singaraja tahun ajaran 2018/2019. Hal ini ditunjukkan dari hasil uji-t dengan SPSS 16.0 for Windows bahwa nilai sig pada kolom sig (2-tailed) dan baris equal variances assumed sebesar 0.000 . Nilai sig ini lebih kecil dari pada 0,05 sehingga sehingga $\mathrm{H}_{\mathrm{o}}$ ditolak dan $\mathrm{H}_{1}$ diterima. Hasil ini menunjukkan adanya perbedaan hasil belajar antara siswa yang dibelajarkan menggunakan model pembelajaran kooperatif tipe NHT dengan siswa yang dibelajarkan menggunakan model pembelajaran konvensional.

Berdasarkan hasil penelitian memberikan beberapa saran, yaitu: 1) Penggunaan model pembelajaran kooperatif NHT dapat dijadikan alternative sebagai acuan para guru penjaskes untuk kualitas pembelajaran lebih bervariasi, menarik, dan menyenangkan bagi siswa, 2) Penggunaan model pembelajaran kooperatif NHT dalam pembelajaran pendidikan penjaskes dapat disesuaikan dengan kemampuan dan karakteristik peserta didik, sehingga peserta didik lebih 
mudah memahami materi yang diberikan dan dapat meningkatkan hasil belajar peserta didik.

\section{DAFTAR PUSTAKA}

Dewi, Komang Ayu Krisna. 2017. Pengaruh Model Pembelajaran Kooperatif Tipe Numbered Head Together (NHT) Terhadap Hasil Belajar Teknik Dasar Passing Bola Basket. Tersedia pada https://ejournal.undiksha.ac.id/inde x.php/JJP/article/view/14806/9073 (diambil pada Kamis, 1 Maret 2018)

Fajrin, Yanuar, Nur, 2014. Penerapan Model Pembelajaran Kooperatif Tipe Numbered Head Together (NHT) Terhadap Hasil Belajar Dribbling Sepak Bola (Studi Pada Siswa Kelas XI SMA Negeri 1 Tarik Sidoarjo). Tersedia pada: Jurnal Pendidikan dan Kesehatan , Volume 02 Nomor 02 ISSN 2338798X:

https://jurnalmahasiswa.unesa.ac.i d (diambil pada Kamis, 1 Maret 2018)

Fariz, 2017. Pengaruh Penerapan model pembelajaran Tipe Numbered Head Together (NHT) terhadap Hasil Belajar IPS Siswa Kelas V SD Negeri 4 Metro Utara, Lampung. Tersedia pada https://digilib.unila.ac.id (diambil pada Jumat, 2 Maret 2018)

Kanca, I Nyoman. 2010. Metode Penelitian Pengajaran Pendidikan Jasmani dan Olahraga. Singaraja: Universitas Pendidikan Ganesha

Slameto, 2003. Belajar dan Faktor-faktor yang Mempengaruhi. Jakarta: PT Rineka Cipta.
Suarjuliasa, Gd. 2017. Pengaruh Penerapan Model Pembelajaran Kooperatif Tipe Numbered Head Together (NHT) Terhadap Hasil Belajar Teknik Dasar Passing Control Sepak Bola Pada Siswa Kelas VII 10 di SMP Negeri 2 Singaraja Tahun Pelajaran 2016/2017. Tersedia pada https://ejournal.undiksha.ac.id/inde x.php/JJP/article/view/12555/7873 (diambil pada 12 September 2018)

Trianto. 2007, Model-model Pembelajaran Inovatif Berorientasi Konstruktivistik. Jakarta: Prestasi Pustaka.

Sugiyono, 2012. Metode Penelitian Kuantitatif Kualitatif dan R \& D. Bandung:Alfabeta. 